\title{
DOES DEMOGRAPHICS MATTER IN LIFELONG LEARNING? A RESEARCH CONTEXT OF VIETNAM
}

\author{
LE THAI PHONG¹, NGUYEN THU THUY², NGUYEN THI HANH ${ }^{3}$, DAU BAO NGOC4,
}

${ }^{1}$ Lecturer, Faculty of Business Administration, Foreign Trade University, Vietnam. T., 2,3Ministry of Education and Training, Vietnam., ${ }^{4}$ Student of Advance Program, K57, ID: 1812280063, Faculty of Business Administration, Foreign Trade University.

Email: lethaiphong@ftu.edu.vn

Received: 05 June 2021, Revised and Accepted: 25 July 2021

\begin{abstract}
Objective: Lifelong learning (LLL) has lately attracted significant attention from the society in general, universities and corporations in particular. For the case of Vietnam, the Government has pledged to create a Lifelong Learning Society. A number of initiatives have been launched to help achieve this goal, including the Southeast Asian Ministers of Education Organization Centre for Lifelong Learning (SEAMEO CELLL) and "Book Day", a day dedicated to encouraging reading and raising awareness of its importance in the development of knowledge and skills. Lifelong learning (LLL) programs are also being adopted at libraries, museums, cultural centers, and clubs in Vietnam. In addition to the effort done by the Vietnamese government, a number of non-governmental, non-profit organizations and educational institutions have started to take action to encourage literacy and lifelong learning. It can be said that education and educational reforms are always the top concern of each country. This study is to investigate about lifelong learning of community with 4 aspects: (1) Learning Competencies; (2) Learning Contexts; (3) Learning Contents and (4) Learning Goals as well as examining the differences in the opinion about lifelong learning between categorical variables. The second purpose of the study is to examine the relationship between an individual's perspective on lifelong learning and their actual learning capacity, as well as learning motive.
\end{abstract}

Methods: The paper deploys primary data collecting from 270 people in different sectors and different occupations. Standard statistical techniques such as mean analysis, OLS multivariable analysis are used to find the answer for proposed hypotheses.

Results: Using a sample of 270 respondents varying in age, gender, and employment status, the authors found that there are differences on the attitudes towards lifelong learning, the motivations and skills needed for this "journey".

Conclusion: From the findings, researchers proposed recommendations to promoting and fostering lifelong learning of community with the case of Vietnam.

Keywords: Lifelong learning, learning society, lifelong learning of community, Vietnam.

(c) 2021 The Authors. Published by Innovare Academic Sciences Pvt Ltd. This is an open access article under the CC BY license (http://creativecommons.org/licenses/by /4.0/) DOI: http://dx.doi.org/10.22159/ijss.2021v9i5.42880. Journal homepage: https://innovareacademics.in/journals/index.php/ijss

\section{INTRODUCTION}

The knowledge-based economy, new technologies, the increasing speed of technological development, and globalization all have an impact on the population's need to upgrade their skills and competencies. As our societies progress toward becoming "knowledge societies," there is an increasing demand for people who are well-prepared for lifelong learning (LLL). For example, European Union member states agreed that developing and implementing coherent and comprehensive LLL strategies is a key educational aim [1]. Lifelong learning is an extensive educational approach receiving much attention not only by European Union but also by the rest of the world.

Effective educational possibilities for lifelong learning must be promoted in the multiple learning environments, including home, school, employment, and the greater political community. Insights obtained from these unique situations must be transformed into wide and successful learning theories, creative and intelligent systems, practices, and evaluations in a variety of professional fields. A lifelong learning strategy allows the finest aspects of school, community, home, and career learning to be combined. In addition, increasing levels of education have been identified as a crucial driver of long-term economic growth in conventional economic research. Individually, employees become more productive as a result of the information and skills they gain via education and training. Education of high quality can increase a population's knowledge and skills beyond what conventional or informal institutions can achieve. For business, educated and highly trained people promote productivity increases and technical development by innovating or imitating procedures created elsewhere. At the societal level, education expansion contributes to the development of social and institutional capital, which has a significant impact on the investment climate and growth; it also contributes to the development of participatory societies, the strengthening of the rule of law, and the promotion of good governance.

Lifelong learning is an ambiguous concept, used in a variety of ways and has a complex history within the field of education [2]. Dunn (2003) revealed that lifelong learning (LLL) includes the skills, knowledge, attitudes and behaviors that people develop as a result of their daily lives [3]. European Communities (2000) defined lifelong learning as "all purposeful learning activity, undertaken on an ongoing basis with the aim of improving knowledge, skills and competence" [1]. Similarly, OECD (1996) states that "lifelong learning is far broader than the provision of second-chance education and training for adults. It is based on the view that everyone should be able, motivated, and actively encouraged to learn throughout life. This view of learning embraces individual and social development of all kinds and in all settings: formally, in schools, vocational, tertiary and adult education institutions; and non-formally, at home, at work and in the community" [4]. Or to put 
it simply: "LLL is a development after formal education: the continuing development of knowledge and skills that people experience after formal education and throughout their lives" [5]. All in all, despite different ways LLL has been conceptualized, they mostly share a basic notion, which is people's participation in deliberate learning throughout their lives for personal and professional fulfillment, as well as to enhance their life quality.

It not only enhances social inclusion, active citizenship and personal development, but also self-sustainability as well as competitiveness and employability [6]. To relate this definition to concepts of educational and psychological science, core determinants for LLL were defined in accordance with the relevant literature [7], [8], [9]). These determinants are independent of specific contextual features (e.g., specific academic subjects, age brackets): (1) the enduring motivation and appreciation for education and learning and (2) the competences for self-regulated learning (SRL). Furthermore, (3) social and (4) cognitive competences were identified as accompanying determinants [10]. Thus, when seeking to improve LLL, these four determinants should be systematically addressed.

LLL also assists individuals in achieving other objectives, such as being more involved in civic life, living a more sustainable lifestyle, and improving their health and well-being. It is also beneficial to society since it reduces crime and promotes communal activities [3]. As a result of the globalization and the growth of the fast-changing knowledge economy, people must upgrade their skills throughout their adult lives to cope with modern living, both at work and at private lives. In recent years, there is an increasingly important basic skill in ever-changing technological universe: ability to learn and adapt to the needed new skills and training [11]

\section{MATERIALS AND METHODS}

As not much data is available about the correlation between an individual's perception of lifelong learning and their learning capacity, we conducted an exploratory study using a short online questionnaire. The questionnaire is divided into two parts. The first part contains questions about people's basic information and their educational background. Questions in the second part address quite directly people's opinion on LLL, their learning habits, where knowledge is obtained, and skills supplement needed.

The sample consists of 270 people from under 18 to over 55 years old living in Vietnam. Respondents were selected by using stratified random sampling techniques. The questionnaire was distributed via various channels: email, google form, and paper-based interview (in case the respondants have little knowledge on ICT).

In this article, we use stratified random sampling, then divide the population (all respondents) into groups according to the criteria of demographic factors such as age, gender, working experience, nature of work, highest degree. Sample size estimated $n=270$. The questionnaire uses a 5-level Likert scale developed by Rensis Likert in 1932, with measuring convention being: " 1 : Totally disagree; 2 : disagree; 3: Neutral; 4: Agree; 5: Strongly agree." We interpret the content and encode the scale of the variables as follows: QD1 represents the extent to which a respondent recognizes the necessity of LLL. The variables are borrowed from European Commision (2003) [12]:

\section{RESULTS AND DISCUSSION}

\section{Descriptive statistics}

Descriptive statistics was employed to describe the researched variables.

\section{Respondents' backgrounds}

The survey was conducted in Vietnam with respondents from diverse educational backgrounds. Undergraduate students accounted for the largest proportion with 102 survey samples, accounting for $37.8 \%$. The lowest rate was $\mathrm{PhD}$ students with merely 3\%. High school students also accounted for a large proportion of $24.8 \%$, followed by college and master students with $14.8 \%$ and $13 \%$ respectively (Table 2 ).
Table 1: Variable development

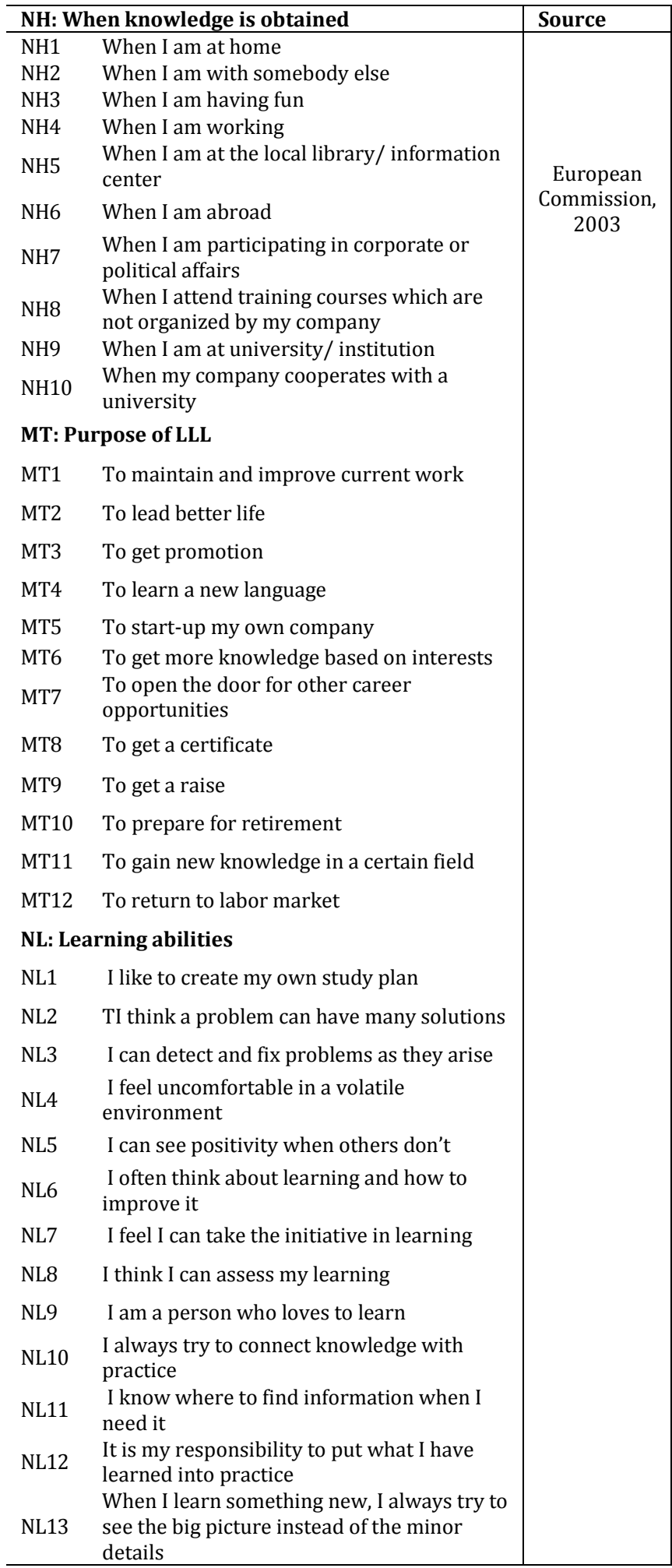

Table 2: Degree distribution of the sample

\begin{tabular}{lll}
\hline Highest degree & Frequency & Percent \\
\hline High school & 67 & 24.8 \\
Vocational & 18 & 6.7 \\
College & 40 & 14.8 \\
University & 102 & 37.8 \\
Master & 35 & 13.0 \\
PhD & 8 & 3.0 \\
Total & $\mathbf{2 7 0}$ & $\mathbf{1 0 0 . 0}$ \\
\hline
\end{tabular}


Table 3 shows that the age of the respondents in the present study covered from under 18 to over 55 years old with mean value of 3.19 and standard deviation of 1,539 . The most common age group was 18 to 25 years old, accounting for $33 \%$ of the total sample collected. Majority of the respondents were 45 to 55 years old $(25.2 \%)$ and $38.5 \%$ of them were students. Employees working under enterprises contract accounted for a lower rate of $21.9 \%$, followed by the unemployed and government employees with the lowest proportions (13\% and $12.6 \%)$.

Table 3: Age distrubtion of the sample

\begin{tabular}{ccc}
\hline Age (years old) & Frequency & Percent \\
\hline$<18$ & 37 & 13.7 \\
$18-25$ & 89 & 33 \\
$25-35$ & 19 & 7 \\
$35-45$ & 47 & 17,4 \\
$45-55$ & 68 & 25,2 \\
$>55$ & 10 & 3,7 \\
\hline Total & $\mathbf{2 7 0}$ & $\mathbf{1 0 0 . 0}$
\end{tabular}

Pupils and students are the most interviewed subjects with 104 answers, accounting for $38.5 \%$. Followed by members of enterprises with 59 votes, equivalent to $21.9 \%$. Government related, farmer and unemployed had similar votes in $12-14 \%$ of the total sample (Table 4).

Table 4: Professionals distribution of the sample

\begin{tabular}{lll}
\hline Nature of work & Frequency & Percent \\
\hline Pupil, student & 104 & 38,5 \\
Government - related & 34 & 12,6 \\
Business organization & 59 & 21,9 \\
Farmer & 38 & 14,1 \\
Unemployed & 25 & 13 \\
\hline Total & $\mathbf{2 7 0}$ & $\mathbf{1 0 0 . 0}$ \\
\hline
\end{tabular}

Lifelong learning related variables

Table 5 illustrates the perception of people about the importance of lifelong learning. As can be seen, LLL is significant and extremely important in roughly $62 \%$ of the data using descriptive statistics. The number of people holding a neutral opinion towards LLL is 65, accounting for $24.1 \%$ of all responses. Meanwhile, only $14 \%$ believe LLL is unimportant.

The purpose of the LLL is summarized in the following table, along with descriptive statistics. Particularly, MT3, MT5, MT10, and MT12 are less identified as LLL objectives when the mean values of the variables are all less than 3. Maintaining and improving current work (MT1) is identified as a goal of LLL with a mean of 3.96 (Table $6)$.

Table 5: People perception on the importance of lifelong learning

\begin{tabular}{ccc}
\hline QD1 & Frequency & Percent \\
\hline 1 & 16 & 5,9 \\
2 & 22 & 8,1 \\
3 & 65 & 24,1 \\
4 & 98 & 36,3 \\
5 & 69 & 25,6 \\
\hline Total & $\mathbf{2 7 0}$ & $\mathbf{1 0 0 . 0}$ \\
\hline
\end{tabular}

Table 6: Descriptive statistics of the variables

\begin{tabular}{|c|c|c|c|c|c|}
\hline & $\mathbf{N}$ & Minimum & Maximum & Mean & $\begin{array}{c}\text { Std, } \\
\text { Deviation }\end{array}$ \\
\hline MT1 & 270 & 2 & 5 & 3,96 & 0,844 \\
\hline MT2 & 269 & 2 & 5 & 3,78 & 0,975 \\
\hline MT3 & 270 & 1 & 4 & 2,66 & 1,06 \\
\hline MT4 & 270 & 1 & 5 & 3,2 & 1,071 \\
\hline MT5 & 270 & 1 & 5 & 2,54 & 0,729 \\
\hline MT6 & 270 & 1 & 5 & 3,72 & 0,893 \\
\hline MT7 & 270 & 2 & 5 & 2,8 & 0,923 \\
\hline MT8 & 270 & 1 & 5 & 3,73 & 1,02 \\
\hline MT9 & 270 & 1 & 5 & 3,29 & 1,162 \\
\hline MT10 & 270 & 1 & 4 & 2,64 & 0,952 \\
\hline MT11 & 270 & 1 & 5 & 3,86 & 1,024 \\
\hline MT12 & 270 & 1 & 5 & 2,57 & 1,094 \\
\hline \multicolumn{6}{|l|}{ Valid } \\
\hline \multicolumn{6}{|l|}{$\mathrm{N}$ (list } \\
\hline wise) & 269 & & & & \\
\hline
\end{tabular}

\section{Correlations between variables}

For further analysis, we use Pearson correlation analysis to examine the association among the variables.

QD1 is significantly correlated with MT1, MT3, MT4, MT5, MT6, MT7, MT10 and MT12. According to the Pearson correlation test results, people who value LLL use it to maintain and improve their current job (rMT1=0.26); to get promoted (rMT3=0.201); to learn a new foreign language (rMT4=0.134); to gain more knowledge based on their interests (rMT6=0,183); and to prepare for retirement (rMT12=0.187). Meanwhile, starting up one's own company; opening up other career opportunities and preparing for retirement do not serve LLL's purpose as data of MT5, MT7 and MT10 are negatively correlated with QD1.

Table 7: Relationship between importance of LLL and people's motivation

\begin{tabular}{|c|c|c|c|c|c|c|c|c|c|c|c|c|c|c|}
\hline QD1 & pearson correlation & ,260** &,-054 & ,201** & ,134* &,$- 354 * *$ &, $183^{* *}$ &,$- 437^{* *}$ &, 026 & ,115 &, $187^{* *}$ & ,113 &,$- 302 * *$ & 1 \\
\hline & Sig. (2-tailed) & ,000 & ,376 & , 001 & ,028 &, 000 & ,003 &, 000 & ,675 & ,058 & ,002 & ,063 &, 000 & \\
\hline & $\mathrm{N}$ & 270 & 269 & 270 & 270 & 270 & 270 & 270 & 270 & 270 & 270 & 270 & 270 & 270 \\
\hline
\end{tabular}

**. Correlation is significant at the 0.01 level (2-tailed) *.Correlation is significant at the 0.05 level (2-tailed)

Learning competence is also correlated with attitudes towards lifelong learning. Specifically, through the Pearson test, QD1 correlates with most types of learning ability, except NL5, NL9, NL10, and NL12 at 5\% significance level. The results show that all types of competencies are positively correlated with QD1, which proves that the more a person thinks lifelong learning is important, the better he or she will have a good learning capacity.

Table 8: Regression between the importance of LLL and people's motivation

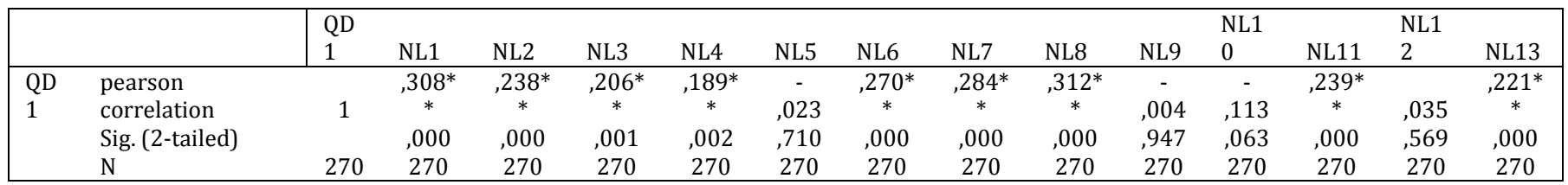

The respondents' university - business cooperation status has a positive relationship with LLL since the regression result between the dependent variable QD1 and the independent variable NH10 (knowledge obtained from the university - business linkage) as 
follows: Alpha $<0.05$ shows that the regression results are statistically significant. Beta $=0.417$ shows that for each unit of knowledge the participants gain from the relationship between university and company
(NH10), the importance of LLL (QD1) will increase by 0.417 units. This also supports the university-company cooperation positively affects the LLL of people hypothesis.

Table 9: University-industry linkages and LLL learning

\begin{tabular}{|c|c|c|c|c|c|}
\hline \multirow[b]{2}{*}{ Model } & \multicolumn{2}{|c|}{ Unstandardized Coefficients } & standardized Coefficients & \multirow[b]{2}{*}{$\mathrm{t}$} & \multirow[b]{2}{*}{ Sig. } \\
\hline & B & Std. Error & Beta & & \\
\hline $\begin{array}{ll}1 & \text { (constant) } \\
& \text { NH10 }\end{array}$ & $\begin{array}{c}2,189 \\
, 392\end{array}$ & $\begin{array}{l}207 \\
, 052\end{array}$ & ,417 & $\begin{array}{c}10,560 \\
7,510\end{array}$ & $\begin{array}{l}000 \\
, 000\end{array}$ \\
\hline
\end{tabular}

Demographic factors are also closely related to attitudes about LLL. Factors such as highest degree, age, working experience, gender, nature of work have been proved to affect LLL (NGUYEN, L., LUU, P. \& HO, H., 2020). However, in this study, regression results show that only age and gender are statistically significant in the association with LLL. Specifically, participants of lower age group (Beta = 0.504 ) and female participants (Beta $=-0.138$ ) tend to value LLL more than other groups.

\section{The difference among various groups}

First, the authors perform test to justify that three observed variables are reliable to measure the construct "Point of view about the important of lifelong learning". The result from IBM SPSS show that the variables meet reliability criteria for measuring the construct with Cronbach's alpha > 0.5 (0.668). Then, the researchers performed ANOVA to compare the means of the construct between demographic categories, below are some notable results:

\section{Between gender}

Table 10: Group Statistics

\begin{tabular}{|c|c|c|c|c|c|}
\hline & gender & $\mathrm{N}$ & Mean & Std. Deviation & Std. Error Mean \\
\hline QD & $\begin{array}{l}\text { male } \\
\text { female }\end{array}$ & $\begin{array}{l}132 \\
138\end{array}$ & $\begin{array}{r}3.9975 \\
3.5193\end{array}$ & $\begin{array}{r}.69614 \\
1.04328\end{array}$ & $\begin{array}{r}.06082 \\
08881\end{array}$ \\
\hline
\end{tabular}

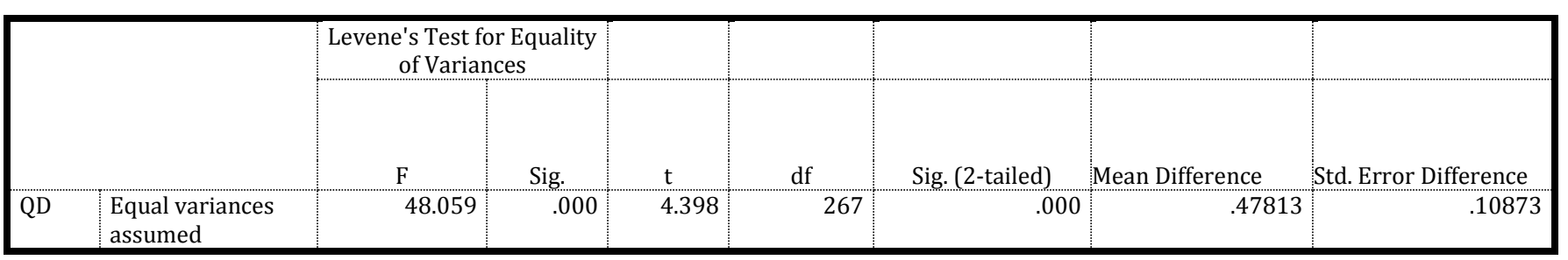

The result from Table 10 suggests that there is a difference in point of view considering the importance of lifelong learning between male and female with a confidence level of $99 \%$. Specifically, the analysis show that male considered lifelong learning is an important aspect while female also feel that it is important but not as much as male (supported by the mean value of male is greater than mean value of female by 0.47

\section{Between age groups}

The analysis reveals that the younger the respondent, the more they acknowledged the importance of lifelong learning in one's life. In specific, the group age consists of under 18 years old respondent consider lifelong learning is much more important than the other groups. Meanwhile, the group of people above 55 years old do not find too much importance in lifelong learning.

\section{Between occupation (nature of the respondent's work)}

Inspecting the differences between people with different working nature, the authors realized that among the five surveyed occupations, farmer and unemployed people do not recognize lifelong learning as an important aspect of their life. It is supported by the below analysis result.

The mean value of "lifelong learning importance" construct of the farmer and the unemployed are much lower than the pupil, student group as well as government-related group and business organization group.

\section{The relation between the point of view about the skills} importance and the need to improve it.

The result suggests that $86.61 \%$ of the respondent agree that skills related to computer, Internet and digital technologies are the most important in the society. In association with the previous figure, about $4.46 \%$ of the people wanted to improve their capabilities at that field which indicates that Vietnamese people acknowledge the important of those ability in digital era and already equipped themselves with the appropriate knowledge.

The two next skills that is viewed important by Vietnamese people are (1) skills related to learning with $84.39 \%$ agree that it is important and (2) problem detecting and solving skill with $82.16 \%$ people agreed about its importance.

\section{Learning context}

The top three context where respondents learn new knowledge or improve their understanding are (1) classes/courses conducted at college/academy/university, (2) participation in work related to the Union at work, and (3) participation in group learning. In addition, each of the demographic groups have different preferable learning context.

\section{Learning competencies}

According to the findings, the top three competencies that respondents choosing are self-direction, critical thinking, and problem-solving.

\section{CONCLUSION}

The findings of the present study implied that people's attitude towards LLL have a significant correlation with their learning competence as well as their age and gender. Moreover, a positive trend is also witnessed in the link between opinion on LLL and university - business learning opportunity. Based on those results, we came up with a few methods to foster LLL in Vietnam community. One of them is enhancing the motive leading to LLL, in this case is maintaining and improving current work. Businesses may want to consider creating continuous training programs as a way to encourage their employees to become adaptive lifelong learners. In addition, promoting the relationship between businesses and universities is essential as it is a potential learning opportunity for most employees. 
It is necessary that the state, government and ministries and related institutions create a suitable environment to promote universitybusiness cooperation by implementing policies that regulate university-business cooperation, such as: promote the socialization of higher education; encourage companies to invest in technological research and development collaboration with universities; create a special mechanism for highly specialized training disciplines in order to strengthen the role of companies in training when collaborating with universities.

For universities, it is crucial to develop clear guidelines and regulations on the mechanism of cooperation with companies. Schools should also facilitate and encourage scientists to actively participate in research, development and technology transfer related to social needs. Involve good company executives and scientists in the university's training and research activities, while ensuring that a team of professors with an entrepreneurial spirit are encouraged to participate in collaborations with enterprises.

Last but not least, corporate executives need to be aware of the importance of selecting and hiring the right human resources, which is very important for the future of companies. You will see partnering with universities as strategic in order to generate business opportunities and serve the long-term development goals of the company itself. Therefore, companies should establish internal guidelines to promote and build a creative culture, and to encourage R\&D activities. There are mechanisms and guidelines to support startups and encourage university researchers to participate in projects and share academic knowledge with companies, etc.

Technology should be incorporated into and used to augment the teaching process at the teaching process at universities, colleges and other educational institutions. Teaching resources, including videos, handouts, and other materials, should be available digitally. Lecturers can help educate and facilitate students on effective and useful ways to improve their digital literacy competency through self-regulated learning strategies. In addition, the authorities should invest more money in building educational and training instititions to create the best and most diverse context for the community to learn.

Coordination among authorities, governments, education and training institutions, and business organizations should be strengthened to support and create conditions for people to study. Dialogues with businesses to give the task of improving the education and skills of employees into the labor agreement should be organized, whereby businesses create specific conditions in terms of time and money, and at the same time encourage employees to participate study and improve skills. Enterprises need to have activities to select and award scholarships (partial or full) to employees achieve high achievements. In addition, government, schools and corporates academic support scholarships should also be awarded to high-achieving or disadvantaged students in order to motivate them for lifelong learning.
The organization of propaganda activities to create motivation for the community, raising their awareness about the benefits of lifelong learning, specially emphasis on 3 key points: lifelong learning helps maintain and better the current job, lifelong learning makes personal life better, and lifelong learning brings great achievements. For each individual in society, it is necessary to equip themselves with the necessary skills and competencies for effective lifelong learning. The ability to develop your own study plan is believed to be the most important for effective learning. Problem-solving is also considered as the factor of paramount importance in lifelong learning.

\section{ACKNOWLEDGEMENT}

This paper is an integral part of Research Project CT.2019.07.05 "University-industry linkages in fostering lifelong learning: international experience and lessons for Vietnam", financed by Vietnam Ministry of Education and Training.

\section{REFERENCES}

1. European Communities, C. O. T. E. 2000. A memorandum on lifelong learning. SEC (2000).

2. Crowther, J. \& suntherland, P. 2008. Lifelong learning: Concepts and contexts, Routledge.

3. Dunn, E. 2003. The Lifelong Learning Strategy for Scotland. Scottish Executive.

4. OECD, 1996. Organisation for Economic Co-operation and Development Education Committee 1996, Lifelong learning for all: meeting of the Education Committee at Ministerial level, Paris: s.n.

5. Encarta, 2008. Lifelong learning. [Online]

6. European Communities, C. O. T. E. 2006. Adult learning: It is never too late to learn. Commission of the European Communities Brussels.

7. Achtenhagen, F. \& Lempert, W. 2000. Kurzfassung des Berichts und des Programms „Lebenslanges Lernen “. Lebenslanges Lernen im Beruf-seine Grundlegung im Kindesund Jugendalter. Springer.

8. Artlet, C., Baumert, J., Julius-Mcelvany, N. \& Penschar, J. 2003. Learners for Life. Student Approaches to Learning. Results from PISA 2000, ERIC.

9. Weinstein, C.E. \& Hume, L. M. 1998. Study strategies for lifelong learning, American Psychological Association.

10. Schober, B., Finsterwald, M., Wagner, P., Luftenegger, M., Aysner, M. \& Spiel, C. 2007. TALK-A training program to encourage lifelong learning in school. Zeitschrift für Psychologie/journal of Psychology, 215, 183-193.

11. Laal, M. 2011. Barriers to lifelong learning. Procedia-Social and Behavioral Sciences, 28, 612-615.

12. European Commission, 2003, Lifelong learning: citizen's view, Luxembourg: Office for Official Publications of the European Communities, 2003 